\title{
Study on methods of design technology for the nightscape of urban gardens
}

\author{
Lu Min ${ }^{1,{ }^{*}, S u n ~ B a o s h a n^{2}, \text { Li Donghe }}{ }^{2}$,LuoXiaonan ${ }^{2}$, and ZhaoPeng ${ }^{2}$ \\ ${ }^{1}$ Shandong Jianzhu University, Jinan 250101, China;
}

\begin{abstract}
As a new form of landscape designing, the garden nightscape is an important part of the urban landscape planning and design. The scientific and reasonable method of design technology for the city garden nightscape can provide foundations and technical supports for the design of garden nightscape and the creation of excellent landscape. The study analyzes and summarizes the application of lighting source, landscape lamps and the landscape lighting technology in the garden. It is indicated that the modern garden nightscape shows the trend of comprehensive utilization of high efficiency, energy saving, low carbon ecology, lighting and decoration, and high technology.
\end{abstract}

\section{Introduction}

As a new form of landscape designing, the nightscape of garden is an important part of the planning and design of urban landscape, and it is also an organic combination of lighting science and garden landscape art. The landscape is not only the reappearance of the daytime landscape, but also the combination of the landscape elements and the lighting effect through the advanced scientific means and rich landscaping techniques. It presents a new landscape at night and creates a refreshing effect ${ }^{[1]}$.

Excellent city landscape is not only the card of the flourishing, fashionable and charming of city, but also to meet the public night leisure, entertainment, fitness and other activities such as lighting requirements. Therefore, it has more requirements on better view of the landscape to improve the city's environmental beauty ${ }^{[2,3]}$. A scientific and reasonable design method of urban garden nightscape can provide foundations and technical guarantee for the design of nightscape and the creation of excellent garden nightscape.

\section{Methods of landscape design technology of garden nightscape}

\subsection{Methods of landscape design technology of garden nightscape}

\subsubsection{Application of natural light source}

The application of natural light in landscape architecture refers to the effect of light and shadow effects of natural light on the visual presentation of the landscape. By interacting with other design elements and controlling the lighting, it is intended to show the texture and color, so that the space becomes both significant and sensible, thus satisfying the functional requirements, cultural needs and spiritual needs of the people. Most of the nightscape in classical gardens is achieved through natural lighting, and the unique atmosphere of the nightscape is formed.

\subsubsection{Application of artificial light source}

The natural light cannot be controlled by designers, so we need to use various types of artificial light for supplement. The artificial light source is the unnatural light source which is created by the needs of people, such as the fireworks, the designed colorful light of candles and other ${ }^{[4]}$. Artificial light has the characteristics of strong maneuverability. It can not only design the color, brightness and direction of the light source, but also form dynamic landscape according to the interval of lighting, and add vitality to the design of nightscape. With the development of science and technology, different kinds of high and new technology are applied in landscape design, especially for the application of nightscape lighting design. The change of multimedia control lighting is gradually applied to the field of artificial light. Artificial light is becoming more and more flexible in the following aspects: building space modeling, artistic conception and scale.

\subsection{Application technology of landscape lamps and lanterns}

\subsubsection{Application of traditional landscape lighting}

Traditional landscape lamps and lanterns refer to ancient lamps and lanterns, which are classical and elegant, and should be used in classical gardens to create a strong

" Corresponding author: Min Lu:1010018258@qq.com 
historical and cultural atmosphere and poetic artistic conception. With the development of era, traditional landscape lighting in the application of modern garden, or maintain the original shape, or some improvement, such as lantern, stone lamp, palace lamp and so on, its fire light source is also replaced by the electric light source.(For example, figure 1)。
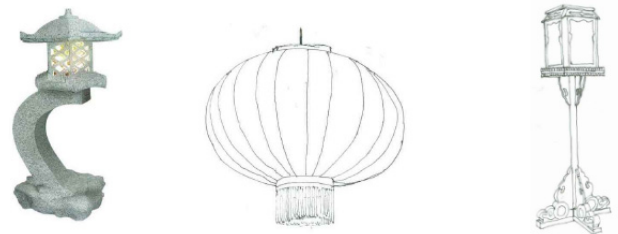

Fig. 1. Traditional landscape lamps and lanterns

\subsubsection{Application of courtyard lamp}

The courtyard lamp is the decorative lamp installed on the top of the pole or hanging on the side of the pillar. It is different from other landscape lighting lamps and can be installed directly. The height of the courtyard lights varies from about 2 meters to 5 meters. According to the different lamp pole and assembly mode of lamps, the courtyard lamp can be divided into top, hoisting and side loading. According to the type of lamp holder, it can be divided into single head, double head and multi head, and long direction columnar lamp and so on ${ }^{[5]}$. The courtyard lamp is small and chic. It is mostly used in the design of the nightscape for small courtyard, and is matched with other landscape elements.

\subsubsection{Application of lawn lamp}

The lawn lamp has small size and its height is generally lower than 1.2 meters. The style of the lawn lamp is rich and diverse, not only includes the concise abstract geometric modeling, but also many kinds of bionic modeling, e.g. the mushroom like, the bean sprout shape and so on, as well as the strong decorative special modeling. In addition, there are stool lamps which are combined with stools, and covered with metal and stone materials on the surface. The way of light emission is divided into lateral light emission (unidirectional and bidirectional), circle light emission, and both lateral and upper light emission, in which the lateral light is the most common. The way of lamps installation includes directly burying and flanging (as shown in Figure 2,3,4). They are generally used in lawns to make the plant nightscape by lighting part of vegetation
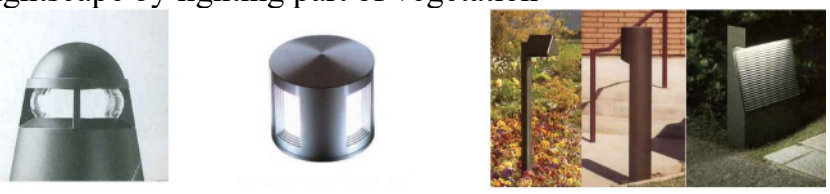

Fig. 2.Short lawn lawn lamp (left / medium), single side light lawn lamp (right)
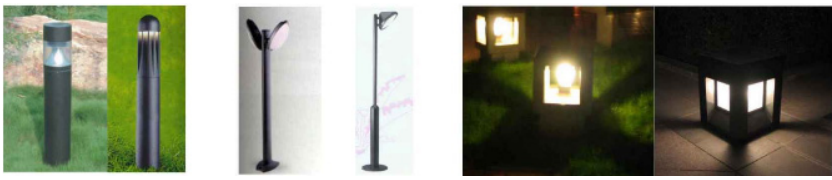

Fig. 3. Lawn lamp (left), stigma lawn lamp (middle), stool lawn lamp (right)
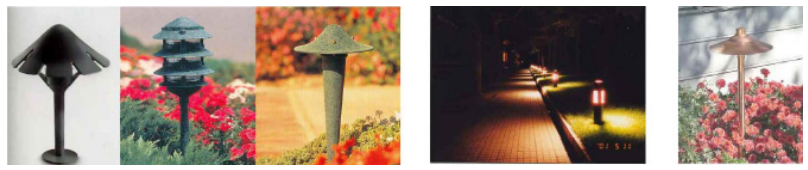

Fig. 4. Special modeling lawn lamp (left), up and down light lawn lamp, low voltage lawn lamp (right)

\subsubsection{Application of decorative lighting products}

Lighting products are divided into two types: light sculpture and decorative lamps. Lighting sculptures are usually designed for specific occasions, therefore they have many different styles; decorative lamps often rely on color light to improve their own ornamental, because it emphasizes the decoration of the appearance (such as Figure 5). The characteristic of the lighting sketch is that the lamp itself is a kind of landscape element, which not only adorns the environment, but to a certain degree also plays a role in lighting at night.

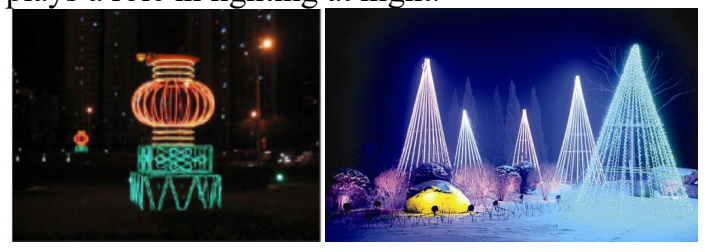

Fig. 5. Decorative lighting products

\subsection{Methods of nightscape lighting technique}

\subsubsection{Floodlight}

Floodlighting is a kind of lighting technique and is common used in nightscape design for gardens. In order to show the exterior modeling and the appearance of the object, the projection distance between the light source and the landscape is designed according to the volume of the garden landscape and the effect that the landscape designer needs to express. So it is also known as facade lighting or projection lighting ${ }^{[6]}$. For the garden nightscape, the panorama can effectively depict the stereoscopic, modeling, decorative color and decoration details of the irradiated objects, in addition to presenting the full view of the scene. The effect of floodlighting is directly affected by the material. Generally, the scene combined with floodlight photography includes garden sketches, fountains and garden buildings. (See Table 1).

Table 1. Floodlight effects on the state of the facade

\begin{tabular}{|c|c|}
\hline $\begin{array}{c}\text { The material state of the } \\
\text { facade }\end{array}$ & Floodlighting effect \\
\hline
\end{tabular}




\begin{tabular}{|c|c|}
\hline rough surface & Diffuse light \\
\hline Smooth surface & Smooth surface \\
\hline $\begin{array}{c}\text { The color is similar to the } \\
\text { color of the light source } \\
\text { (congruent) }\end{array}$ & Elevation of color \\
\hline
\end{tabular}

Use floodlights to illuminate all the elements of the surface of the facade to obtain a bright surface.You can clearly see the details of the scene on this luminous surface, such as the details of the scene, the facade, the decoration and other elements. These elements can increase the interest and readability of scenery, and enable viewers to enjoy a visual sense of life in close viewing. When depicting the surface elements of a scene, we should make rational use of light and shade, shadow and color change based on the features of the surface elements of the scene. As a result, we can create a sense with rhythm that breaks away from the two-dimensional plane, highlights the focus, and shows the stereoscopic and formal beauty of the scene. (For example, Figure 6)

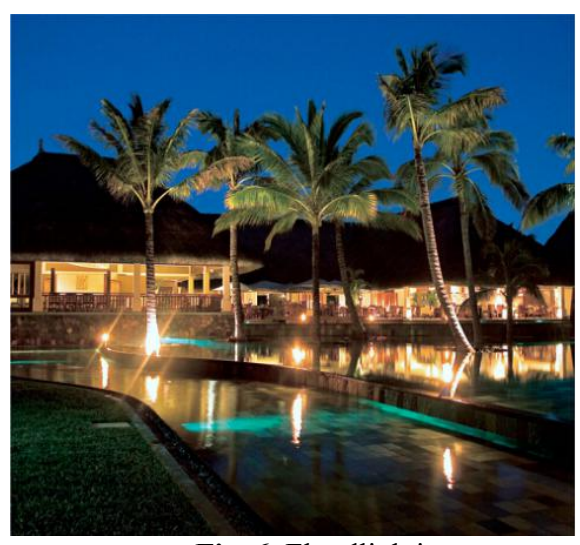

Fig. 6. Floodlighting

\subsubsection{The internal light illumination}

The internal light illumination is mainly a kind of lighting technology which is illuminated from inside to outside, usually combined with the garden architecture. It not only meets the indoor lighting function, but also enhance the visual impact through the transparent material and the outside night landscape. The interior light illumination reflects the continuity of the interior and exterior space of the landscape, and requires that the building to have facade paved with transparent material. It includes two forms of expression, the first is that the transmission light is completely dependent on the indoor light, and the second is that by setting up special light transmitters in the portico, balcony and glass curtain wall of the building, which need to show the effect of nightscape, so as to form a light emitting or luminous surface. (For example, Figure 7).

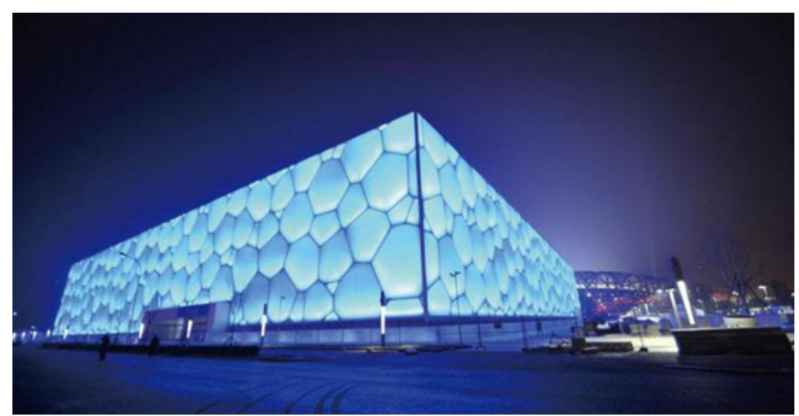

Fig. 7.Light transmittance

\subsubsection{Outline lighting}

The utilization of outline lighting is to show the whole form and volume of garden architecture. It is usually applied by installing lamp belt along the buildings or other special parts. The common light sources are neon lights, incandescent lamps, LED and so on. It is very suitable for the traditional garden architecture. This method can only highlight the beauty of the shape and landscape of the garden building, and is weak in the lighting function. It is usually designed in combination with other lighting techniques with strong lighting function. (For example, figure 8)

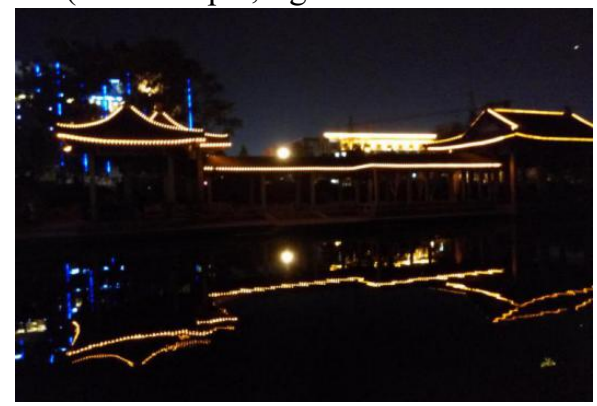

Fig. 8. Contour lighting

The focus lighting is a way that aims to show the beauty of the scenery, by highlighting the illumination of a certain part of the scene. With the wide application of LED light source to landscape lighting, this lighting mode has been applied reasonably. Unlike traditional light sources, LED has the features of light weight, small size and high luminous efficiency, which are fully displayed in focus lighting. For example, in the flower lighting, we can use $1 \mathrm{~W}$ and $3 \mathrm{~W}$ white LED to focus on the unique features of scenery.

\subsubsection{Other lighting technology methods}

Astigmatic lighting is generally used in landscape lighting in the garden, such as platform, step, low plant bushes, garden road and other areas. The height of the lamps is low, and the light beam is usually round to provide no glare lighting well.

Moonlight lighting is a new concept in outdoor nightscape lighting design. The specific method is to install the lamps in a suitable location on the tree, such as the tall trees and branches, or imitate the natural moonlight to make light and shadow mottled lighting effect by lighting through the leaves to the ground. 
High-tech lighting: with the continuous progress and development of science and technology, more and more high-tech optical technologies and principles are widely used. Some high tech lamps and light control technologies, such as holographic projection, laser, and computer ray control technology, which can produce special lighting effects, have been applied to the garden nightscape. In view of high-tech lighting, people have a brand-new understanding of the nightscape of gardens.

\section{Conclusion}

With the wide application of lighting technology, the integration of new materials and technology has led to the endless emergence of lighting products. The application of high and new lighting technology in the garden nightscape has greatly enriched the expressive force of modern gardens. Moreover, it has also restored the traditional style of the gardens. The lighting technology combined with beautifying function breaks through the traditional single lighting function, improves the overall effect of landscape, and forms the development trend of modern landscape in pursuit of high efficiency, energy saving, ecological low carbon, stressing on both lighting and decoration, and the comprehensive application of high-tech lighting.

\section{References}

1. X.B.Xun Light lite. The room of lighting mentality -- a preliminary study on design technique of nightscop lighting of outdoor.4,73(2003)

2. C.C.Cang. low Car Wor. Analysis of nightscape luminance and light reflection of building materials and lighting energy saving . 21,188(2015)

3. J.J.Li. Urban Prob.Discussion on urban night planning: a case study of Guangzhou nightscape lighting planning.6,30(2006)

4. Y.Z.Yang . Jiangxi Mater. Build. Discussion on the importance and energy saving methods of urban nightscape lighting under the new situation.13, 38(2015)

5. N.H.Li. Sci. Tech.Application of energy saving monitoring system for street lamp and night view lamp.18,129(2015)

6. N.Liu. Shanxi Arch.Study on lighting design of scene space . 41 113(2015) 